\title{
A combined strip theory and Smoothed Particle Hydrodynamics approach for estimating slamming loads on a ship in head seas
}

\author{
Daniel Veen ${ }^{1}$ and Tim Gourlay ${ }^{2}$ \\ Centre for Marine Science and Technology, Curtin University, Western Australia \\ GPO Box U1987, Perth, WA 6845, Australia \\ 1daniel.j.veen@gmail.com \\ 2 (corresponding author) t.gourlay@cmst.curtin.edu.au, Phone: +61 89266 7380, Fax: +61 892664799
}

\begin{abstract}
Smoothed Particle Hydrodynamics (SPH) is a mesh-free Lagrangian numerical method suited to modelling fluids with a freely deforming surface. A two-dimensional SPH algorithm has been developed and applied to the problem of ship keel and bow-flare slamming. Freely decelerating drop tests of a model flared hull section were used as a basis for an initial validation of the SPH model. Relative vertical velocity profiles measured during tow tank experiments were then imposed on two-dimensional SPH models and reasonable agreement between the experimental and numerical slamming pressures was found. Finally, relative vertical velocity profiles calculated using SEAWAY software were implemented in the SPH algorithm, so as to simulate slamming on a typical V-form hull model.
\end{abstract}

Keywords: smoothed particle hydrodynamics; ship slamming; head seas

\section{Introduction}

Slamming in head seas is an important issue for a wide range of vessels, from small planing craft with V-shaped bow sections, to large passenger or cargo ships with bulbous bows. During a major slamming event, the bow forefoot emerges clear of the water and then re-enters, causing the hull to experience large impact pressures that have the potential to damage the hull plating. These high impact pressures in turn produce large global loads on the ship, resulting in whipping of the entire hull structure. This subsequent whipping has been known to cause damage to ships, as noted by Andrew and Lloyd (1982) and Yamamoto et al. (1985).

Slamming, an impulsive phenomenon, has previously been categorised into four major types: hull bottom, bow flare, bow stem and wet-deck slamming (Korobkin 1996). Hull bottom slamming occurs after the keel of the ship rises above the water surface and impacts heavily during re-entry (see Figure 1). During a bow flare slam, the largest pressures are experienced nearer the knuckle as the keel does not necessarily emerge from the free surface, while a bow stem slam typically occurs when a wave breaks over the bow. Lastly, wet-deck slamming occurs on multi-hulled ships when the water surface meets the cross-deck structure. In this study only hull bottom and bow flare slamming were considered, for which example conditions are illustrated in Figure 1.

Previous studies have used two-dimensional model tests, three-dimensional model tests, full scale trials and a variety of theoretical and numerical methods in order to simulate and predict slam events. A brief review of the published work is contained in the following sections. 


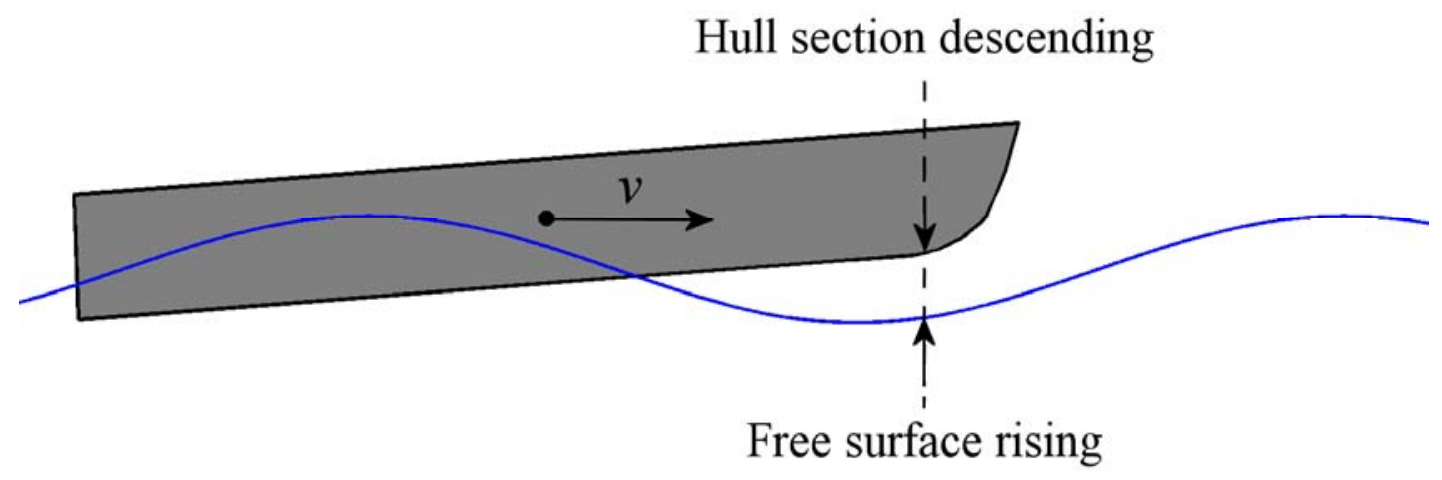

Figure 1: Precursor to hull bottom slam. The bow forefoot of a V-form hull moving at forward speed $v$ has emerged clear of the water and has begun to move back towards the surface at large relative vertical velocity.

\subsection{Two-dimensional model tests}

In general the hull shapes of large ships vary gradually in the longitudinal direction and so a two-dimensional approach is often used to model slamming (Lloyd 1989). These two-dimensional methods model each section of the hull striking the water surface independently by imposing a calculated relative vertical velocity. The local fluid pressures measured at each hull section are ultimately combined to form a picture of the global loads experienced by the hull during a slam event.

Under this two-dimensional assumption, the impact velocity and subsequent slamming pressures for a given hull section shape may be determined using model tests with twodimensional hull sections. These model tests have been completed using a variety of techniques, for example Breder (2005) used a ram moving at constant vertical velocity to study the free surface impact of two-dimensional wedges while Hagiwara and Yuhara (1974) allowed the models to decelerate freely during the drop tests. For nonflared hulls (e.g. wedges), the maximum slamming pressure is observed to occur near the keel, so similar results are obtained from the constant-velocity and freelydecelerating methods. Drop tests have also been performed on flared hull sections (Aarsnes 1996). In this case, the decelerating velocity profile has an important effect on the measured slamming pressures higher up the hull section.

In comparison with three-dimensional model and full-scale tests, the two-dimensional method has been found to consistently overestimate slamming pressures (SNAME 1989). In two-dimensional experiments water can only be diverted transversely, while in the three-dimensional case water can also be diverted longitudinally which tends to dilute the pressure as the hull impacts the water surface.

Bearing in mind the conservative nature of the two-dimensional approximation, twodimensional wedge drop test results have been used to develop empirical methods for predicting peak slamming pressure, typically as a function of deadrise angle and impact velocity (see Lloyd 1989). When combined with a chosen threshold slamming pressure, a slamming event can then be defined based on the deadrise angle and relative vertical velocity at impact (Conolly 1974). Such methods are commonly employed in seakeeping software (e.g. SEAWAY) to determine the frequency of slam events. 


\subsection{Three-dimensional model tests and full-scale trials}

As model tests conducted in two dimensions miss the three-dimensional effects associated with varying longitudinal hull shape, many three-dimensional hull forms have been tested in tow tanks or ocean wave basins at varying wave heights, wave headings and ship speeds. Early studies published by Ochi $(1958,1964)$ investigated the slamming pressures experienced near the keel by typical U- and V-shaped slender hulls, which led to the development of an empirical slamming prediction method (Ochi and Motter 1973). This method defines a slam event based on a threshold relative vertical velocity, which is presumed to scale with ship length according to Froude scaling.

Flared hulls often experience large impact pressures on the flared section as well as on the keel. In fact, full-scale trials on ships have shown that bow flare slamming, rather than keel slamming, is typically the more violent form experienced by frigates (Hay et al. 1994) and containerships (Vulovich et al. 1989). Yamamoto et al. (1985) observed significant damage on the flared section of a containership's hull due to bow flare slamming. Theoretical analyses completed by Arai et al. (1995) and Zhao and Faltinsen (1993) demonstrated that flared bow sections are indeed subjected to larger slamming pressures than simpler U- or V-shaped sections.

Bow flare slamming is more complex than keel slamming, as the magnitude of the slamming pressure is dependent on the relative velocity profile through the entire water entry process. Hermundstad and Moan (2005) published one of the few ocean wave basin studies of bow flare slamming where the relative motions of the bow and the water surface were measured along with the corresponding slamming pressures. This investigation is of particular importance as the experiments can easily be reproduced numerically in order to validate theoretical methods.

Slamming of catamarans entails additional difficulties due to the enclosed nature of the hull beneath a catamaran's cross-deck. For a catamaran with a centre bow, the centre bow's additional buoyancy helps to prevent water impacting the top of the arches. However, high slamming pressures may be experienced when the motions are large enough that water does impact the top of the arches. This type of slamming has been measured at full scale (Thomas et al. 2003) and also analysed using two-dimensional drop tests (Whelan 2004). Significant slamming loads have also been measured on the flat cross-deck of catamarans without a centre bow (Steinmann et al. 1999).

\subsection{Theoretical and numerical methods}

The water entry of a two-dimensional model hull section has long been the principal technique for simulating the slamming problem. An early conformal mapping solution for a two-dimensional wedge developed by Wagner (1932) is still used for validation studies today. In recent years, the water entries of wedges and general hull section shapes have been modelled using more advanced methods such as the Finite Difference Method (Arai and Tasaki 1987), Volume of Fluid Method (Arai et al. 1994) and Boundary Element Method (Zhao et al. 1996, Sun and Faltinsen 2008). However, many of these methods suffer from an inability to model large deformation and fragmentation of the fluid, limiting their ability to accurately simulate the water entry beyond separation of the jet.

Stavovy and Chuang (1976) modelled three-dimensional keel bottom slamming by relating the problem geometrically to the impact of a two-dimensional wedge with the 
appropriate relative impact velocity. Troesch and Kang (1988) developed a simplified potential flow theory for slamming of hull shapes in two- or three dimensions. They found that for slender hulls, the three-dimensional results closely matched the twodimensional results for each hull section, suggesting the use of a strip theory approach to hull slamming. This idea was extended in Finn et al. (2003) with a combined strip theory and simplified two-dimensional potential flow impact theory. Another strip theory method for nonlinear bow flare slamming was given by O'Dea and Walden (1984) and compared to model test results for a frigate.

\section{Smoothed Particle Hydrodynamics}

Smoothed Particle Hydrodynamics (SPH) offers an alternative method to calculate keel slamming and bow flare slamming on ships with arbitrary shape. It is a mesh-free computational method originally developed by Gingold and Monaghan (1977) and Lucy (1977) for astrophysical applications involving complex boundary deformations. As such, it is well suited to free surface hydrodynamic problems with large free surface deformations and fracture.

The SPH method is based on the Euler equations, namely the continuity equation

$$
\frac{d \rho}{d t}=-\rho \nabla \cdot \boldsymbol{u}
$$

and rate of change of momentum equation,

$$
\frac{d \boldsymbol{u}}{d t}=-\frac{1}{\rho} \nabla P+\boldsymbol{g}
$$

where $\rho$ is the fluid density, $P$ the pressure, $\boldsymbol{u}$ the fluid velocity and $\boldsymbol{g}$ the acceleration due to gravity. The evolution of an individual fluid particle's properties is governed by these equations of motion.

Although water is nearly incompressible, the fluid compressibility is retained so that a direct time-stepping method can be employed to evolve the position, velocity, pressure and density of each Lagrangian fluid element. The fluid pressure and density are related through the liquid equation of state (White 1999),

$$
P=P_{S}\left(\left(\frac{\rho}{\rho_{0}}\right)^{\gamma}-1\right)
$$

where $P$ is the pressure above atmospheric of a given fluid particle, $\rho_{0}$ is the fluid density at standard atmospheric pressure, and the index $\gamma$ is typically 7 . The scale factor $P_{S}$ is proportional to the fluid bulk modulus $K$, i.e. $P_{S}=K / \gamma$. The sound speed $c_{S}$ is also related to $P_{S}$ through

$$
P_{S}=\frac{c_{s}^{2} \rho_{0}}{\gamma}
$$

The combination of equations $(1,2$, and 3$)$ is commonly used to describe the transmission of sound waves through water (Jensen et al. 1994), but the equations also apply equally to the bulk fluid flow. The high sound speed of water demands a very small time step by the Courant-Freidrichs-Lewy stability criterion, which in turn forces 
a long inefficient computation time. So in order to decrease the computation time and minimise the subsequent numerical drift the sound speed is lowered (Monaghan 1994), in effect artificially increasing the fluid compressibility (see equations 3 and 4). Provided the Mach number remains below 0.1 the bulk fluid flow is well predicted, though the magnitude and speed of pressure waves within the fluid does differ from the real case.

The properties of each individual particle are calculated at each time step by way of an integral interpolation. For example,

$$
f(\mathbf{r}) \approx \int_{\Omega} f\left(\mathbf{r}^{\prime}\right) W\left(\mathbf{r}-\mathbf{r}^{\prime}\right) d \mathbf{r}^{\prime}
$$

The approximation of the function $f$ at the point of interest $\mathbf{r}$ becomes exact as the kernel $W$, also known as the smoothing function, approaches the Dirac delta function. In practice the kernel is broader than the Dirac delta, encompassing a small number of particles in a local region, rather than just the single point of interest. One particular numerical advantage of the SPH interpolation lies in the calculation of spatial derivatives, which are more accurate and stable than standard finite-difference methods.

The solid wall boundary conditions are modelled using the ghost particle technique (Colagrossi 2004, Veen 2010), which is analogous to the method of images commonly used for potential flow (Streeter 1961). In this approach, particles near the boundary are mirrored across the boundary to create ghosts with identical pressures, densities and mirrored velocities. This symmetry enforces the boundary condition of zero flux through the wall, whilst allowing an (inviscid) free-slip condition along the boundary.

\section{Free-falling hull section impacts in two dimensions}

The SPH algorithm outlined in the previous section was validated against experimental drop test data of a variety of hull section shapes, including two-dimensional wedges and a flared bow section (Veen 2010). As most large ships have hull forms more complex than a wedge, particularly near the bow, the flared section examined by Aarsnes (1996) was a particularly useful validation case.

The free falling $0.32 \mathrm{~m}$ beam drop test model was instrumented with four pressure sensors placed from the keel to the knuckle in the centre of the $1.0 \mathrm{~m}$ long, $261 \mathrm{~kg}$ model (see Figure 2a). Two force transducers were also positioned between the hull section and the falling rig in order to determine the total load during impact. Free in the vertical direction only, the model was allowed to fall from a height of $0.32 \mathrm{~m}$ above the still water surface.

The Aarsnes (1996) hull section SPH simulation was conducted in a tank $2.4 \mathrm{~m}$ wide and $1.0 \mathrm{~m}$ deep containing 384000 fluid particles. The sound speed in this case was set to $100 \mathrm{~m} / \mathrm{s}$ in order to avoid compression effects and also reduce overall computation time (see Section 2). At time $t=0$, the hull section was released from just above the still water surface with an initial velocity calculated from the experimental drop height (the vertical velocity profile can be seen in Figure 2b). An illustration of the pressure field surrounding the hull section $0.06 \mathrm{~s}$ after initial impact with the still water surface can be seen in Figure 3. 


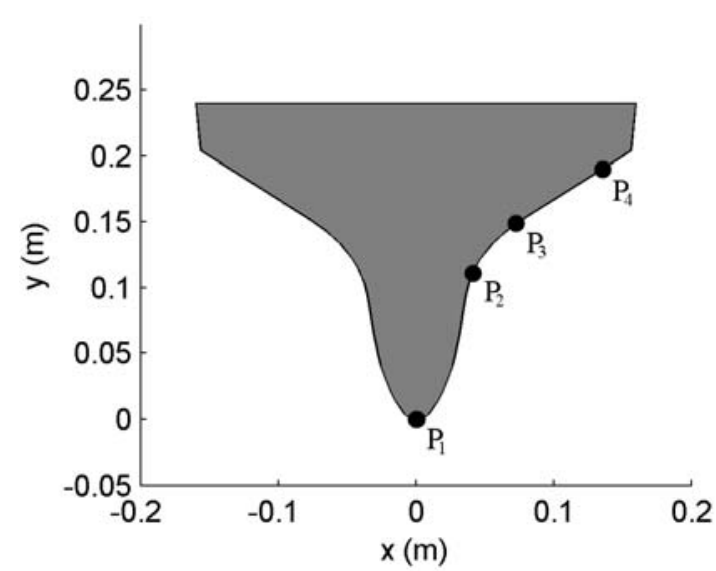

(a)

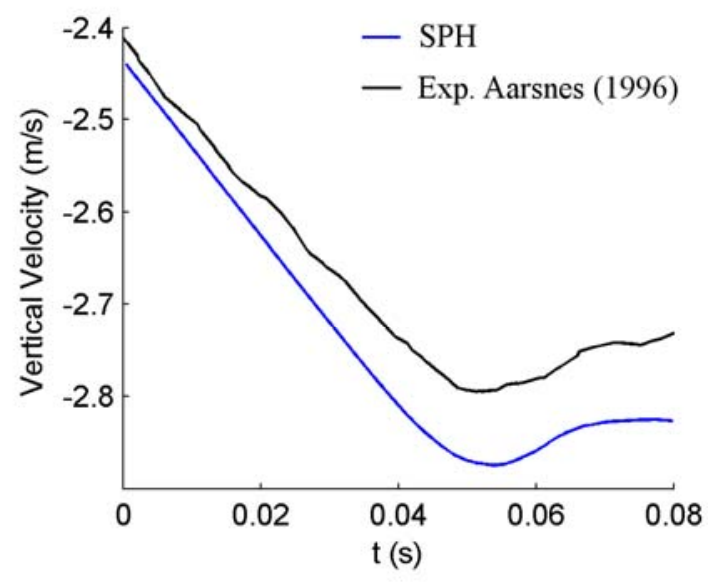

(b)

Figure 2: (a) The ship bow section studied by Aarsnes (1996), indicating the positions of the four pressure sensors. (b) The vertical velocity profile when dropped from a height of $0.32 \mathrm{~m}$.

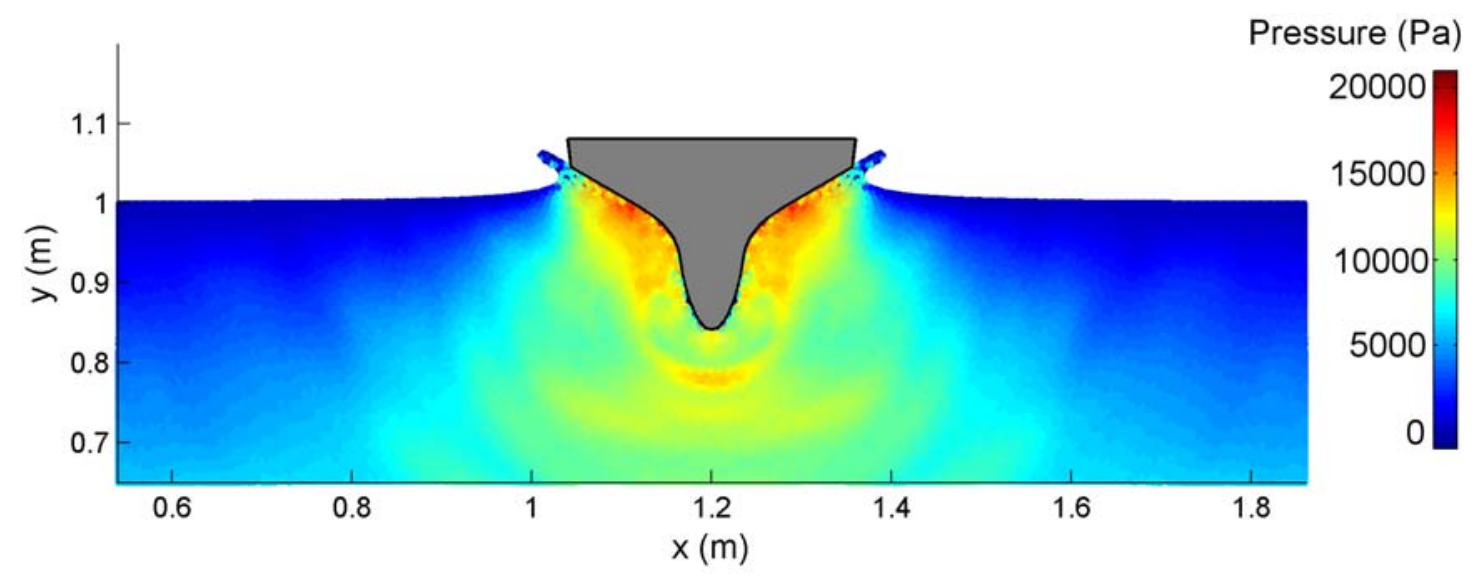

Figure 3: SPH pressure field surrounding the Aarsnes (1996) hull section $0.06 \mathrm{~s}$ after initial impact with the still water surface.

At the moment of initial impact the pressure sensor on the keel, $\mathrm{P}_{1}$ records a peak pressure of $20 \mathrm{kPa}$ in both the experimental and SPH data (see Figure 4a). Once the keel penetrates the surface, the pressure quickly drops before gradually rising as the section entry speed increases. Pressure of this magnitude is not experienced at any other point during the water entry and is a prime example of keel bottom slamming.

The SPH pressure sensor $\mathrm{P}_{3}$ located on the flared part of the hull section records a peak pressure of approximately $15 \mathrm{kPa}, 0.06 \mathrm{~s}$ after initial impact (see Figure 4b). This peak pressure corresponds with the high pressure located adjacent to the hull surface in Figure 3 and is only slightly higher than the $14 \mathrm{kPa}$ obtained by Aarsnes (1996). The slight discrepancy may stem from friction in the testing rig slowing the experimental hull section's entry into the water, which could not be carried through to the SPH simulation. Further drop tests from differing heights showed a similar trend (Veen 2010), with good agreement between the experimental results of Aarsnes (1996) and the SPH simulation. 


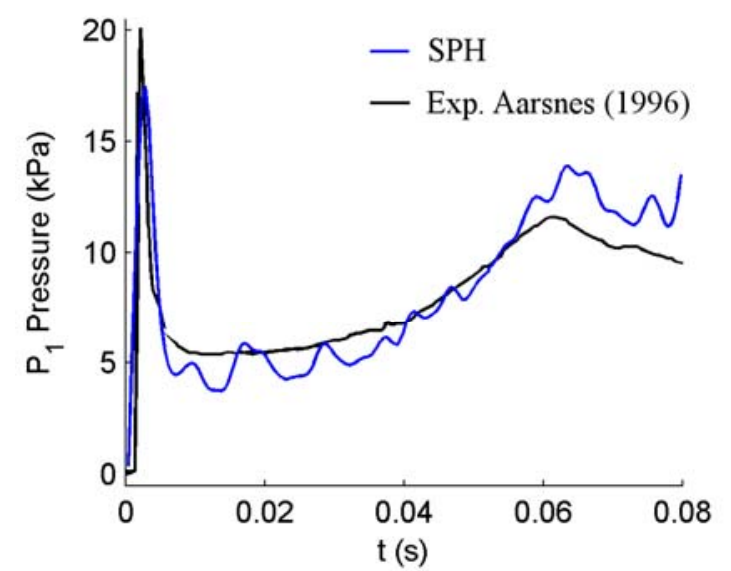

(a)

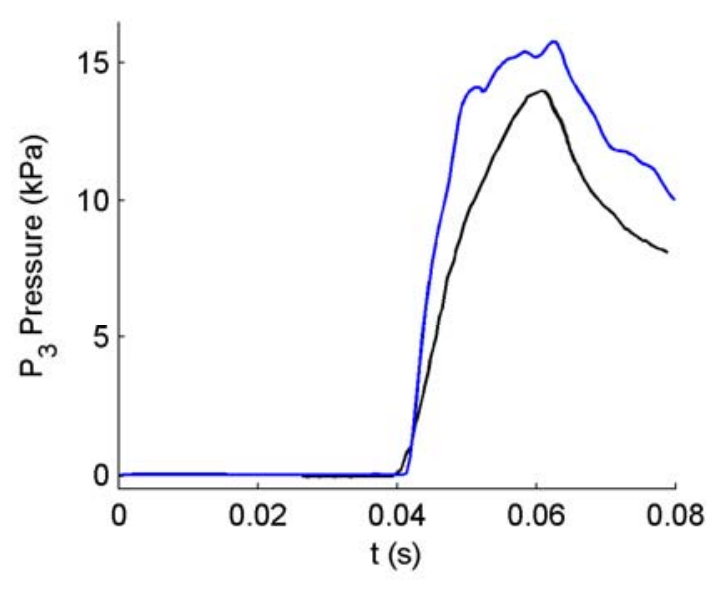

(b)

Figure 4: The fluid pressure recorded (a) at the keel, and (b) on the lower part of the flared section.

\section{Hull section impacts with prescribed velocity profile}

Drop tests such as those analysed in the previous section yield a velocity profile that is not always indicative of that actually experienced at sea. In order to assess slamming pressures over an entire hull section, the vertical velocity profile throughout the entry process is important. For the extreme case of two identical SPH wedges breaking the free surface at the same speed, one forced (constant speed) and the other freely decelerating (drop test), the impact pressures at the keel were found to be similar. However, further above the keel the simulated pressures were much smaller for the freely decelerating case (Veen and Gourlay 2011).

Therefore, in order to accurately describe slamming pressures over an entire hull section, as is crucial for bow flare slamming analysis, the correct velocity profile throughout the slamming event must be used. Hermundstad and Moan (2005) and Sebastiani et al. (2001) demonstrated that for minor slamming of a ship in head seas, the relative vertical velocity profile at each section is sinusoidal and unaffected by the local slamming loads. Consequently, for minor slamming the ship motions can be calculated independently of the slamming analysis, as described in Lloyd (1989).

The experiments of Hermundstad and Moan (2005) were simulated using SPH, with the intention of testing the ability of the two-dimensional method to accurately model slamming pressures on hull sections with a known relative vertical velocity profile. These experiments were conducted on a self-propelled 1:21.6 scale model of the $120 \mathrm{~m}$ car carrier Autoprestige in regular head seas with height $0.10 \mathrm{~m}$ and period $1.9 \mathrm{~s}$. Pressure transducers were mounted beneath the knuckle at $0.05 L_{P P}$ (length between perpendiculars) aft of the forward perpendicular, as illustrated in Figure 5a. The measured relative vertical velocity profile at this hull section, which was used for the $\mathrm{SPH}$ analysis, is illustrated in Figure 5b. 


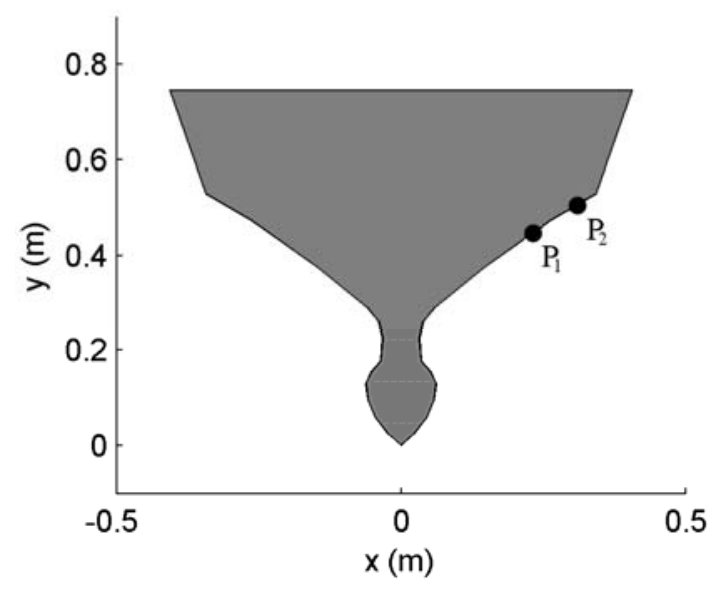

(a)

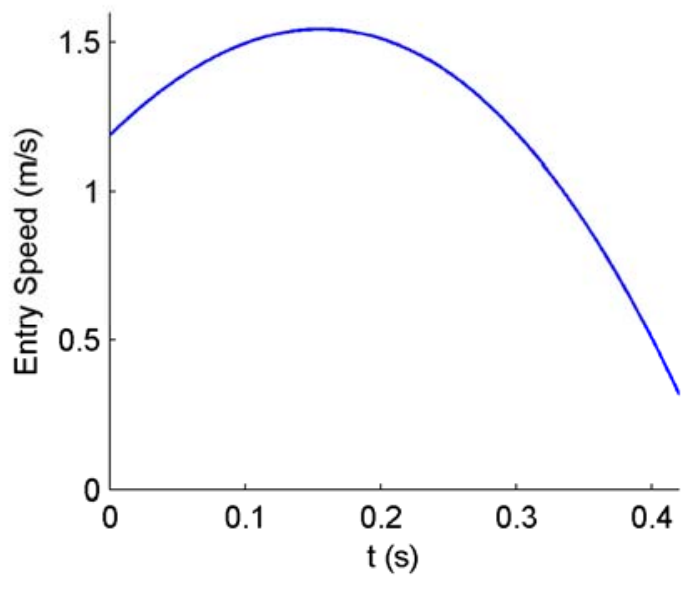

(b)

Figure 5: Hermundstad and Moan (2005) bow flare slamming model tests. (a) Location of pressure transducers $P_{1}$ and $P_{2}, 0.05 L_{P P}$ aft of the forward perpendicular. (b) Measured relative vertical velocity profile, following initial impact of this section.

The two-dimensional SPH simulation was performed at the same scale as the model tests, using a resolution of 200 particles per metre. A finite fluid domain was utilised, with width of $3.5 \mathrm{~m}$ (4.3 times the model beam) and depth $1.5 \mathrm{~m}$, and an artificiallylowered sound speed of $100 \mathrm{~m} / \mathrm{s}$ was used in order to decrease computation time and decrease numerical drift. Wall boundary conditions were enforced by approximating the curved surface using short straight-line segments and the ghost particle technique, as described in Veen (2010).

The computed pressure field surrounding the SPH hull section during bow flare slamming $0.30 \mathrm{~s}$ after initial impact with the free surface is given in Figure 6. At this point in time the fluid pressure immediately adjacent to both pressure sensors is slightly elevated, which is also evident in the SPH and experimental pressure traces in Figure 7.

The comparison between predicted and measured slamming pressures at the two pressure gauges $\mathrm{P}_{1}$ and $\mathrm{P}_{2}$ shows good general agreement, with near identical peak pressure recorded at $\mathrm{P}_{2}$ (see Figure 7). The $\mathrm{SPH}$ calculations produce pressure traces that are slightly more oscillatory than the experimental values, particularly at $\mathrm{P}_{1}$. It is thought that these pressure oscillations are due to the small fluid domain and/or lowered sound speed used in the SPH calculations. Analysis of the effect of fluid sound speed in SPH calculations is described in Veen (2010); the effect on pressure waves was inconclusive due to the differing effects of numerical drift and artificial viscosity at different sound speeds and time step sizes.

Apart from the unresolved pressure oscillations, the results have demonstrated that it is possible to calculate the fluid pressure surrounding a complex three-dimensional hull geometry using the two-dimensional SPH algorithm and prescribed water entry velocity profile. 


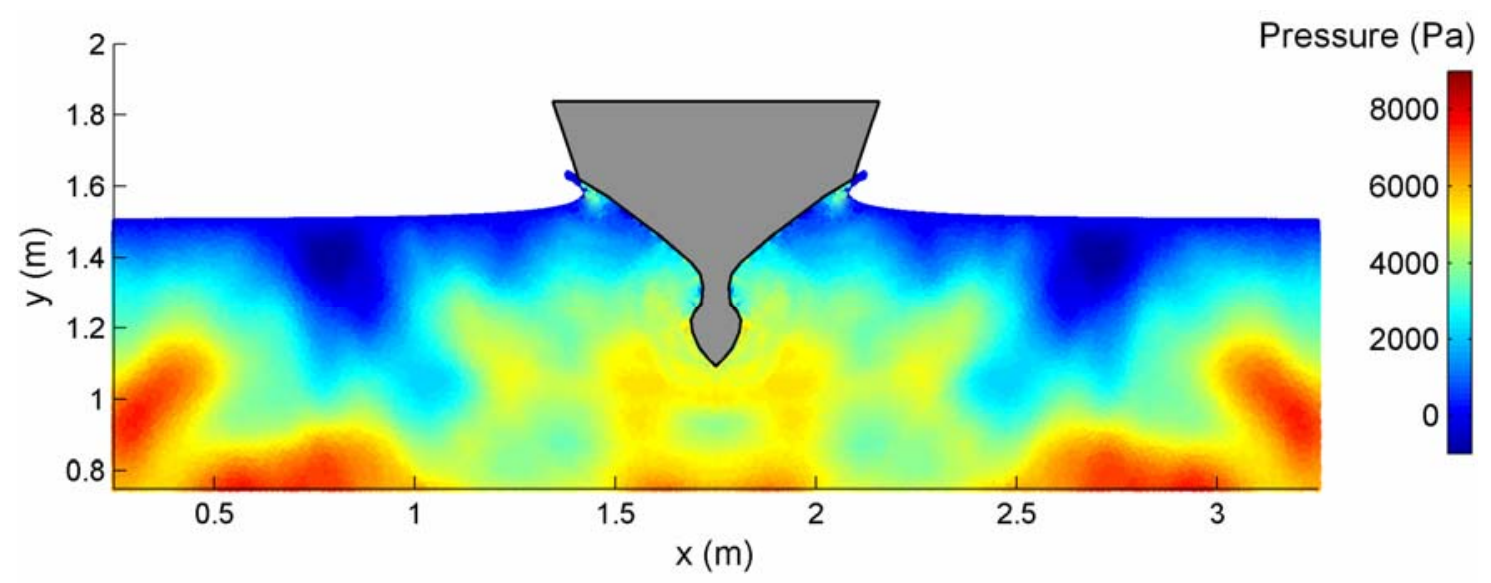

Figure 6: SPH pressure field surrounding the Autoprestige hull section $0.30 \mathrm{~s}$ after initial impact with the still water surface.

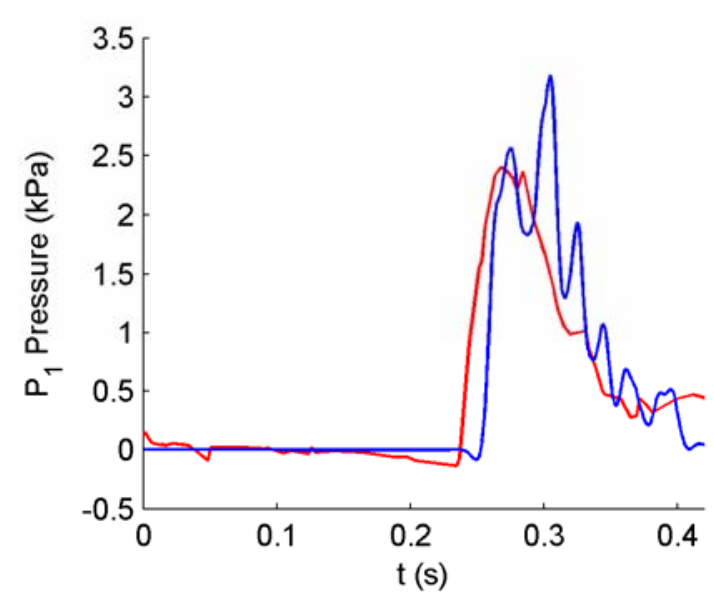

(a)

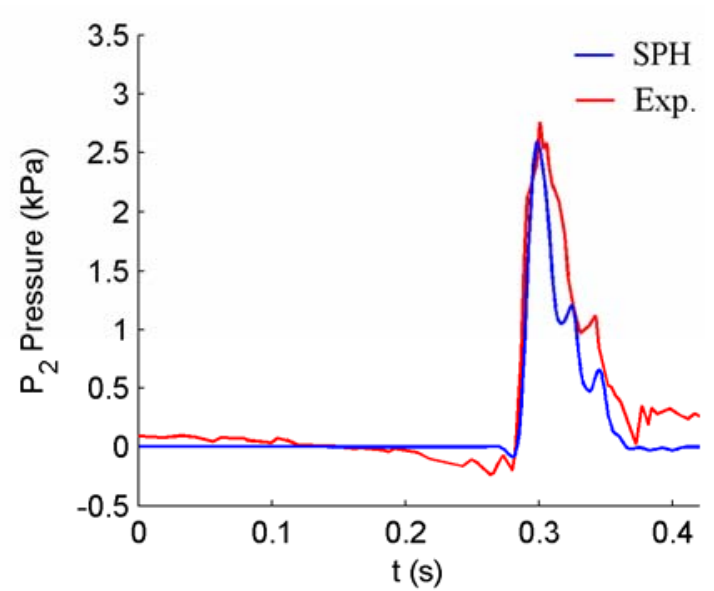

(b)

Figure 7: SPH and experimental pressure signals (Hermundstad and Moan, 2005) recorded at slamming panels (a) $\mathbf{P}_{1}$ and (b) $\mathbf{P}_{2}$.

\section{Combining strip theory and two-dimensional SPH}

During a minor slam event the global motions and slamming loads can be calculated independently of each other. This approach was outlined by Lloyd (1989), where the linear ship motions in the frequency domain are employed. Hermundstad and Moan (2005) also calculated the ship motions and loads independently, first by calculating the nonlinear ship motions in the time domain and then by implementing a boundary element method to determine the slamming pressures with reasonable agreement.

A similar approach can also be applied, using either linear or nonlinear ship motions, to calculate the slamming loads with the two-dimensional SPH method. As an example of this technique, the model tests of Ochi (1958) have been simulated through a combination of SEAWAY, to predict the relative vertical velocity profile at each hull section, and the two-dimensional SPH method to predict the slamming pressures on each hull section.

In order to validate this joint strip theory and SPH approach, the V-form hull of Ochi (1958) was simulated at a variety of forward speeds in regular waves. The V-form hull plan and the location of the pressure transducers are illustrated in Figure 8. 


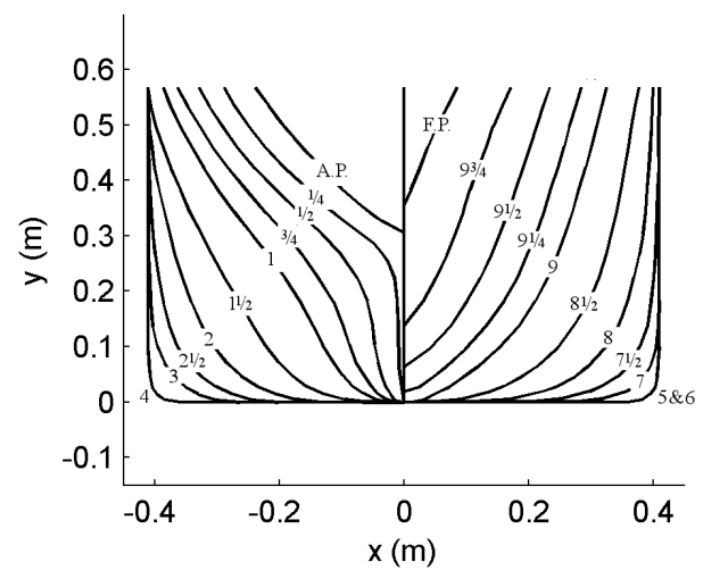

(a)

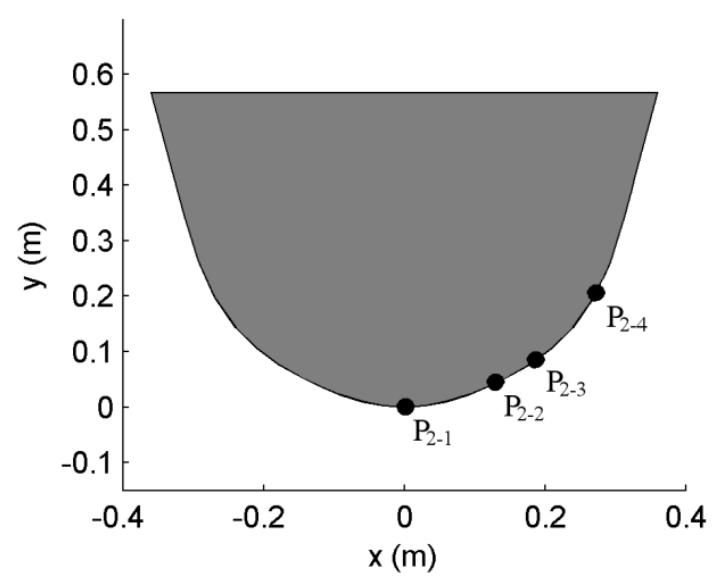

(c)

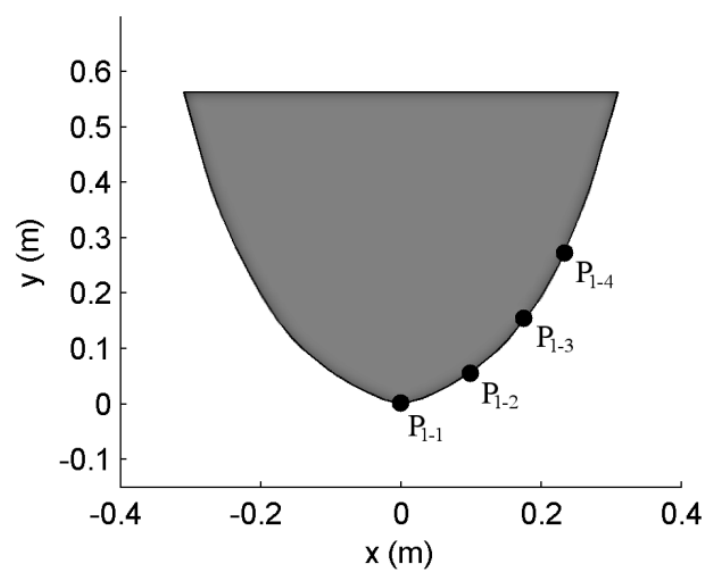

(b)

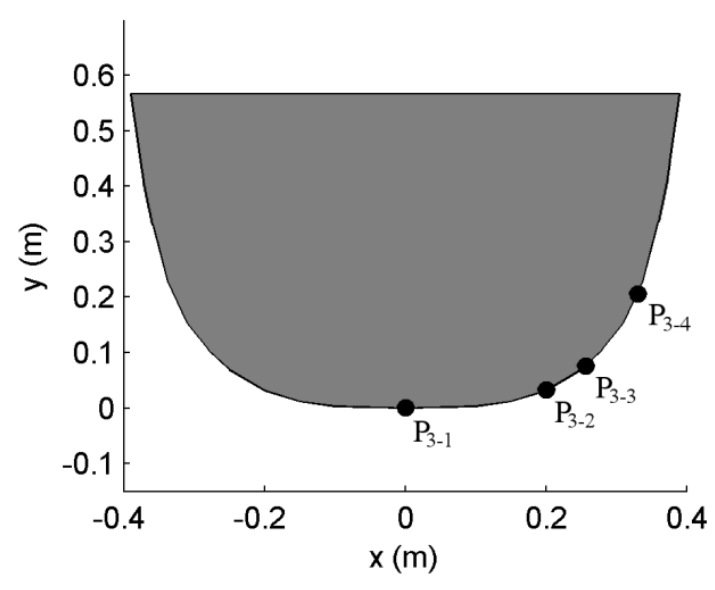

(d)

Figure 8: Details of V-form hull tested by Ochi (1958). (a) The body plan and the location of the pressure transducers at stations (b) 9.07, (c) 8.67 and (d) 8.26.

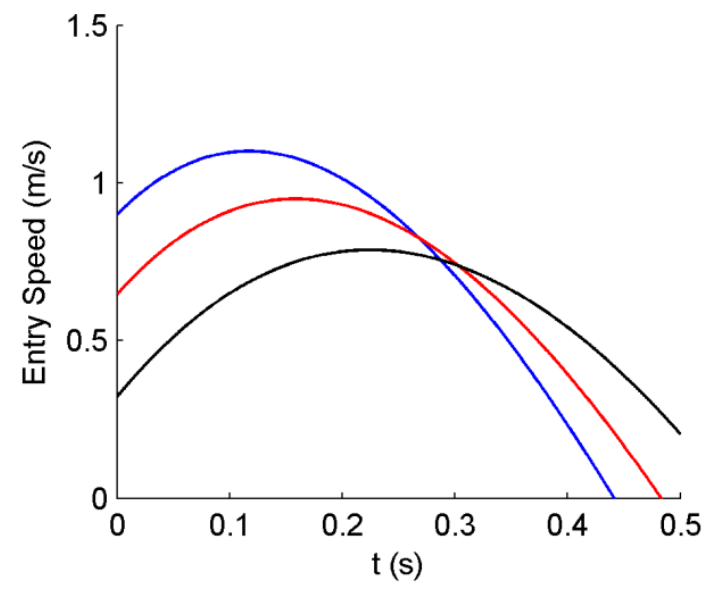

(a)

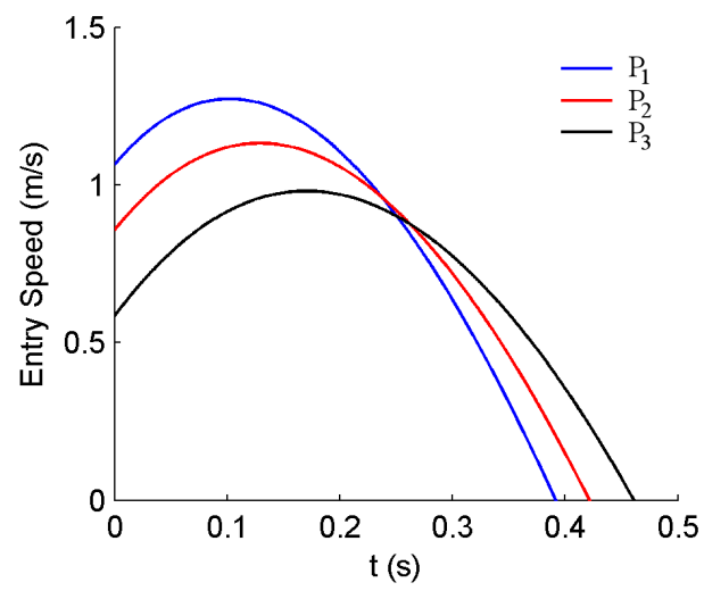

(b)

Figure 9: Relative vertical velocity between hull section and wave surface, calculated using SEAWAY. The time origin lies at the initial keel impact following bow forefoot emergence. (a) Model speed 1.6m/s. (b) Model speed $2.0 \mathrm{~m} / \mathrm{s}$. 
The Ochi (1958) experiments were performed on a self-propelled model in regular head seas, with wavelength equal to the hull's length between perpendiculars $(6.00 \mathrm{~m})$. In order to study the effect of forward speed, model tests were completed at 0.8- 2.8 $\mathrm{m} / \mathrm{s}$, which is the approximate speed range over which emergence of the bow forefoot occurred.

To simulate the model tests, the ship motions were first calculated using SEAWAY (Journée and Adegeest 2003), a linear strip theory code. Only the calculated relative vertical velocity was extracted, as the keel of the $\mathrm{V}$-form hull has no rake at the stations being considered. For hulls with raked keels, the relative longitudinal velocity component may also be taken into account, as described in Stavovy and Chuang (1976).

The calculated relative vertical velocity profiles varied considerably over the range of forward speeds. Example profiles at three stations for forward speeds of $1.6 \mathrm{~m} / \mathrm{s}$ and $2.0 \mathrm{~m} / \mathrm{s}$ are illustrated in Figure 9. Unfortunately the measured relative vertical velocity profiles were not published by Ochi (1958), so the accuracy of the ship motions predictions cannot be checked directly in this case.

Following the calculation of the relative vertical velocity profiles, the two-dimensional SPH algorithm was then implemented. Each of the three hull cross-sections of interest (see Figure 8) were then forced, via the calculated relative vertical velocity profiles, into a tank containing still water (2.4 m wide and $1.0 \mathrm{~m}$ deep) represented by 384000 $\mathrm{SPH}$ particles. The positions of the SPH particles during a simulation of the Ochi Vform model at a forward speed of $1.6 \mathrm{~m} / \mathrm{s}$ are illustrated in Figure 10, with the fluid particles at each hull section given a different color for clarity.

Ochi (1958) measured the peak pressure at the keel of each hull section using $0.02 \mathrm{~m}$ diameter brass strain gauges. Near the bow, at stations 8.67 and 9.07, the peak SPH pressure at the keel was in fair agreement with the experimental peaks over the entire speed range (see Figure 11). However, the peak pressures recorded by the SPH model at station 8.26 are approximately double those measured in the tow tank by Ochi (1958). One possible explanation for this discrepancy is the compression of air immediately adjacent to this much flatter part of the keel, effectively softening the impact experienced. Air has not been considered in the present SPH algorithm.

As mentioned previously, the ship motions results were not published by Ochi (1958), therefore it cannot be determined whether the differences in peak pressure are attributable to the ship motions or SPH calculations in this case. Further experimental data are required to assess the combined strip theory / SPH method more thoroughly. 


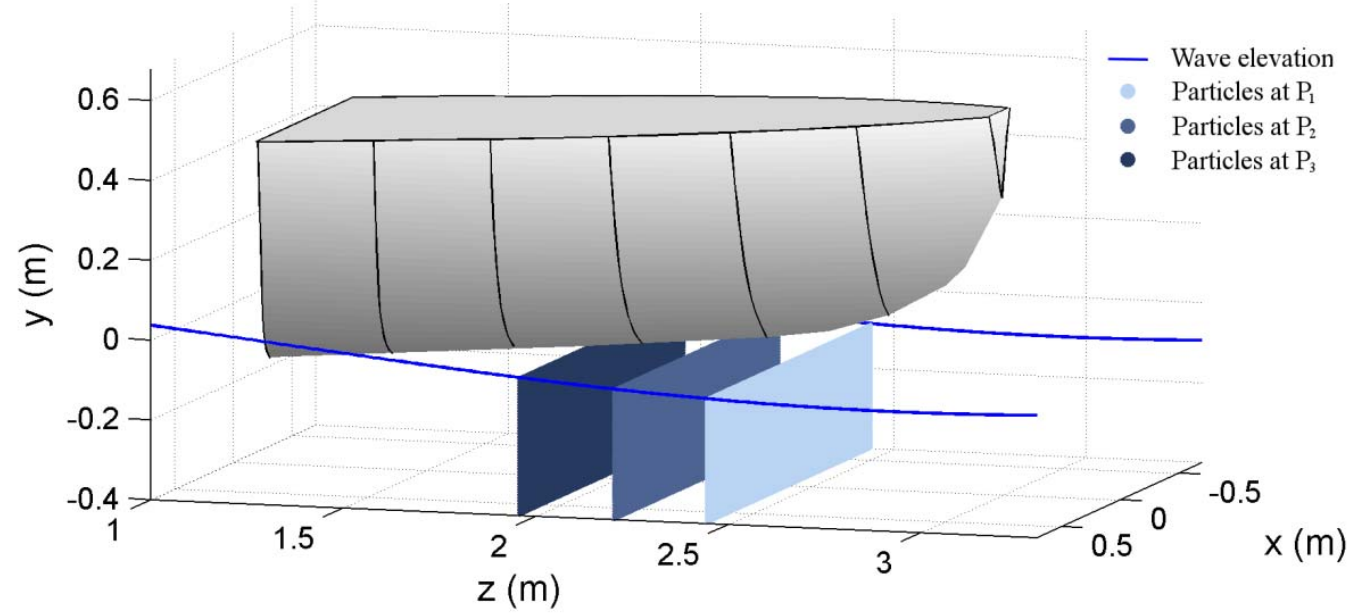

(a)

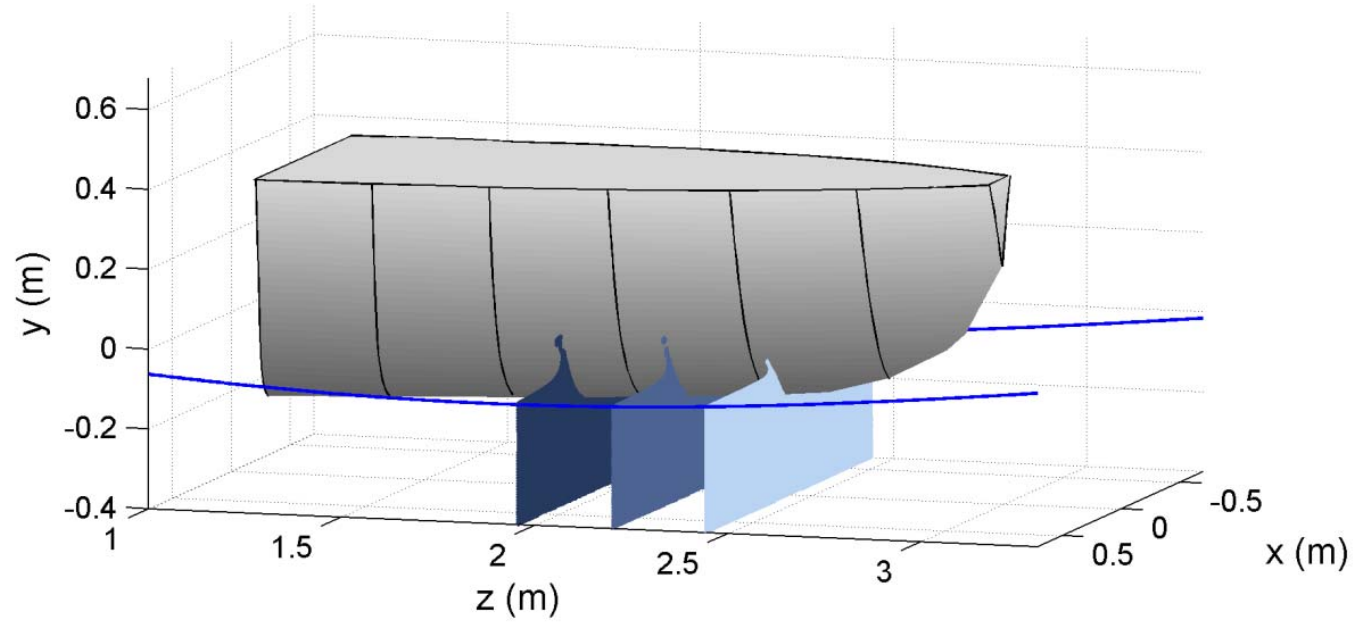

(b)

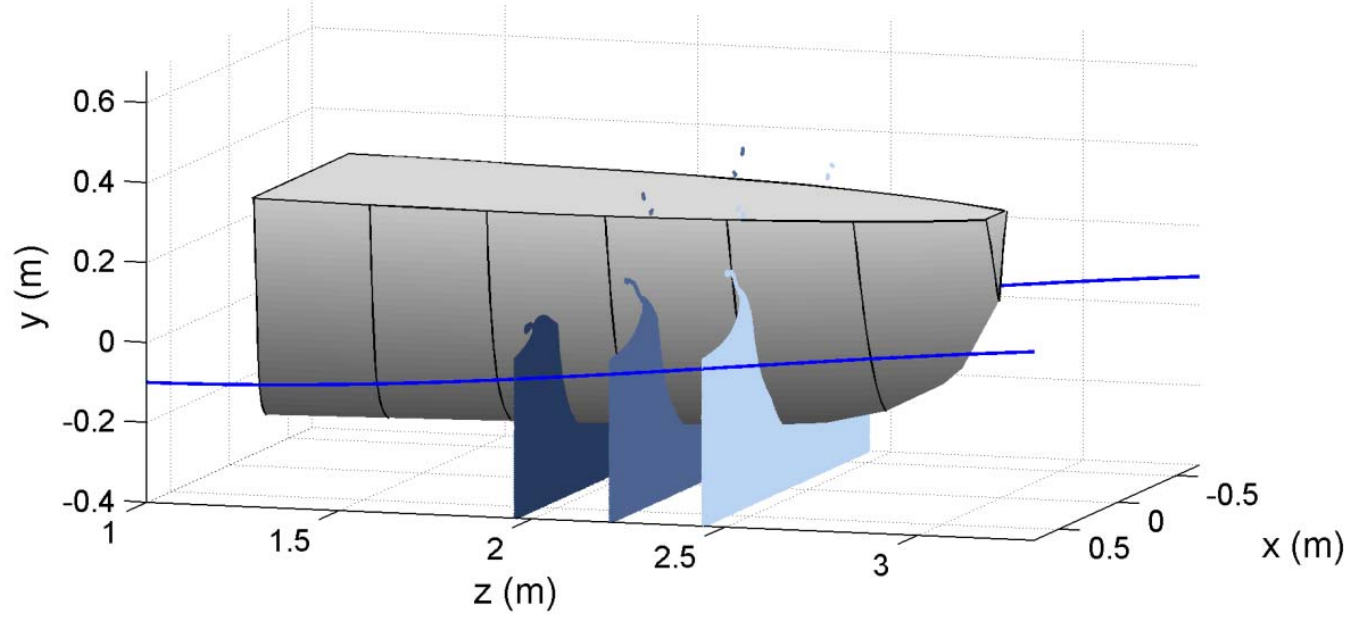

(c)

Figure 10: The SPH fluid particle positions during a simulation of the Ochi (1958) model tests at stations 8.26, 8.67 and 9.07 for a model forward speed of $1.6 \mathrm{~m} / \mathrm{s}$. The particles are illustrated (a) $0.07 \mathrm{~s}$, (b) 0.13s, (c) $0.33 \mathrm{~s}$ after initial impact of the bow forefoot (which occurred at station 8.26).

The undisturbed wave profile is also shown. 


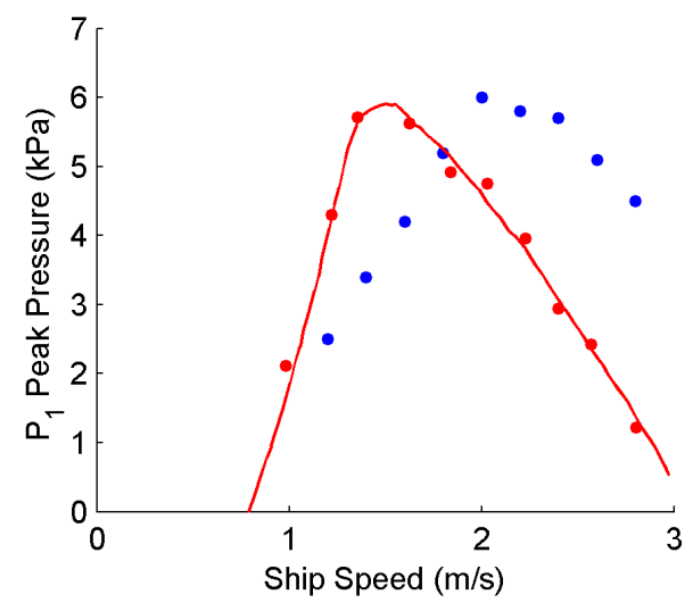

(a)

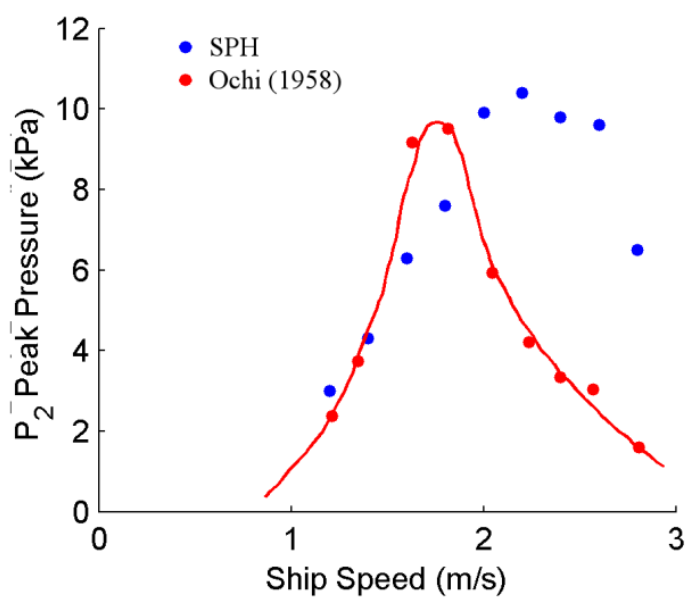

(b)

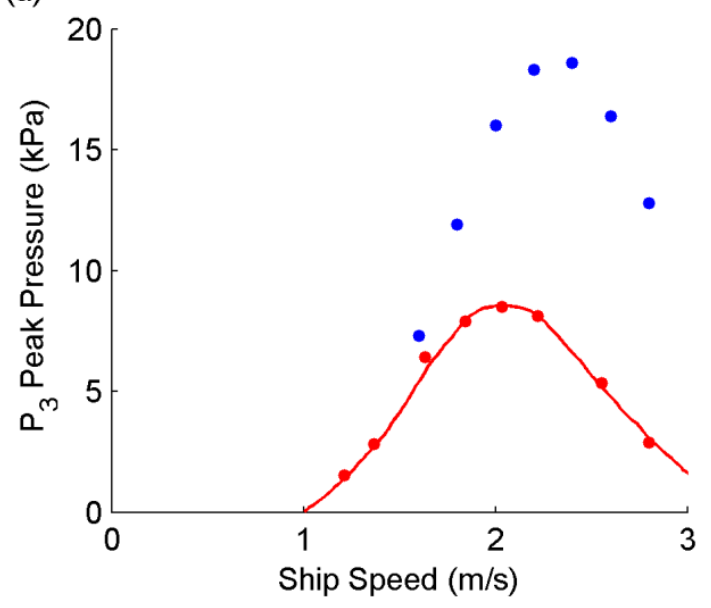

(c)

Figure 11: Peak slamming pressures in the SPH-simulated model tests of Ochi (1958) at (a) station 9.07, (b) station 8.67 and (c) station 8.26.

\section{Conclusions and future directions}

The SPH algorithm has been applied to two-dimensional hull impact problems in order to simulate ship slamming. The method is able to calculate accurate slamming pressures for a wide variety of two-dimensional hull section shapes and vertical velocity profiles. This mesh-free method is also able to cope with bulbous or knuckled bow sections, jet formation and splashes.

For minor slamming of a ship in head seas, previous authors have demonstrated that the ship motions and slamming calculations are effectively decoupled. This suggests the use of a standard strip theory for calculating relative vertical velocities, combined with a two-dimensional hull section impact analysis to calculate the resultant slamming pressures. Such a method has been described and tested here, using the SPH algorithm to simulate slamming on two-dimensional hull sections. A validation of the developed algorithm against the freely decelerating drop test results of Aarsnes (1996) showed good agreement. A comparison with the results of Hermundstad and Moan (2005) also demonstrated good agreement when using the measured relative vertical velocity profile. However, comparison with the Ochi (1958) results showed only fair agreement when using the full strip theory / SPH approach. 
For wedge-shaped bow sections, strip theory has previously been combined with empirical two-dimensional wedge impact results and found to over-predict measured three-dimensional slamming pressures (SNAME 1989, O’Dea and Walden 1984). This is thought to be at least partly due to longitudinal water diversion in the real threedimensional case. For this reason, future development of the SPH algorithm will focus on three-dimensional modelling of the full ship hull and wave profile interaction during a slam event. It is still not recommended to calculate the overall ship motions using SPH, as the method shows significant drift when run over long time periods and is best suited to short-duration, high-impact events. Ship motions are still best calculated using strip theory (or another standard seakeeping method, e.g. panel method), and the calculated ship motions used as an input to the three-dimensional SPH slamming analysis.

The nature of the SPH governing equations and boundary conditions means that extension of the two-dimensional algorithm to three dimensions is relatively straightforward. However, three-dimensional SPH simulations will be extremely computationally intensive, so simulations will initially be run at low resolution on high-end PCs, and at high resolution only on a high performance computer. The situation is helped by the fact that slamming problems are of very short duration, which keeps the computational effort reasonable.

\section{References}

Aarsnes, J.V., 1996. Drop test with ship sections - effect of roll angle. Report No. 603834.00.01, Norwegian Marine Technology Research Institute, Trondheim.

Andrew, R.N., Lloyd, A.R.J.M., 1981. Full-scale comparative measurements of the behaviour of two frigates in severe head seas. The Naval Architect 1, 1-31.

Arai, M., Tasaki, R., 1987. A numerical study of water entrance of two-dimensional wedges. In: Proceedings of the 3rd International Symposium on Practical Design of Ships and Mobile Units, Trondheim.

Arai, M., Cheng, L.Y., Inoue, Y., 1994. A computing method for the analysis of water impact of arbitrary shaped bodies. Journal of the Society of Naval Architects of Japan 176, $233-240$.

Arai, M., Cheng, L.Y., Inoue, Y., Miyauchi, T., Ishikawa, M., 1995. A study of slamming characteristics and optimization of bow forms of ships. In: Proceedings of the 6th International Symposium on Practical Design of Ships and Mobile Units, Seoul.

Breder, J., 2005. Experimental testing of slamming pressure on a rigid marine panel. MEng Thesis, Royal Institute of Technology, Stockholm.

Colagrossi, A., 2004. A meshless lagrangian method for free-surface and interface flows with fragmentation. PhD Thesis, Università di Roma, Rome.

Conolly, J.E., 1974. Standards of good seakeeping for destroyers and frigates in head seas. In: Proceedings of the International Symposium on the Dynamics of Marine Vehicles and Structures in Waves, No. 8, London, U.K.

Finn, P.J., Beck, R.F., Troesch, A.W., Shin, Y.S., 2003. Nonlinear impact loading in an oblique seaway. Journal of Offshore Mechanics and Arctic Engineering 125, 190 197. 
Gingold, R.A., Monaghan, J.J., 1977. Smoothed Particle Hydrodynamics: Theory and application to non-spherical stars. Monthly Notices of the Royal Astronomical Society 181, 375 - 389.

Hagiwara, K., Yuhara, T., 1974. Study of wave impact load on ship bow. Japan Shipbuilding and Marine Engineering 8 (4).

Hay, B., Bourne, J., Engle, A., Rubel, R., 1994. Characteristics of hydrodynamic loads data for a naval combatant. In: Proceedings of the International Conference on Hydroelasticity in Marine Technology, edited by O. M. Faltinsen, Rotterdam.

Hermundstad, O.A., Moan, T., 2005. Numerical and experimental analysis of bow flare slamming on a Ro-Ro vessel in regular oblique waves. Journal of Marine Science and Technology 10, $105-122$.

Jensen, F.B., Kuperman, W.A., Porter, M.B., Schmidt, H., 1994. Computational Ocean Acoustics. American Institute of Physics Press.

Journée, J.M.J., Adegeest, L.J.M., 2003. Theoretical manual of strip theory program “SEAWAY for Windows", TU Delft Report 1370.

Korobkin, A.A., 1996. Water impact problems in ship hydrodynamics. In: Advances in Marine Hydrodynamics, edited by M. Ohkusu, Boston.

Lloyd, A.R.J.M., 1989. Seakeeping: Ship Behaviour in Rough Weather. Ellis Horwood.

Lucy, L.B., 1977. A numerical approach to testing the fission hypothesis. The Astronomical Journal 82 (12), 1013 - 1024.

Monaghan, J.J., 1994. Simulating free surface flows with SPH. Journal of Computational Physics 110, 399 - 406.

O’Dea, J.F., Walden, D.A., 1984. Effect of bow shape and nonlinearities on the prediction of large amplitude motions and deck wetness. In: Proceedings of the $15_{\text {th }}$ ONR Symposium on Naval Hydrodynamics, Hamburg.

Ochi, K., 1958. Model experiments on ship strength and slamming in regular waves. Transactions of the Society of Naval Architects and Marine Engineers 66, 345 - 383.

Ochi, M.K., 1964. Prediction of occurrence and severity of ship slamming at sea. In: Proceedings of 5th O.N.R. Symposium, Bergen, Norway.

Ochi, M.K., Motter, L.E., 1973. Prediction of slamming characteristics and hull responses for ship design. Transactions of the Society of Naval Architects and Marine Engineers 81, 144 - 176.

Sebastiani, L., Valdenazzi, F., Grossi, L., Kapsenberg, G.K., 2001. A theoretical/experimental investigation of the slamming pressures on fast monohull vessels. In: Proceedings of the 6th International Conference on Fast Sea Transportation, Southampton, UK.

SNAME, 1989. Principles of Naval Architecture, Ed. Edward V. Lewis. Society of Naval Architects and Marine Engineers Publications, Jersey City.

Stavovy, A.B., Chuang, S-L., 1976. Analytical determination of slamming pressures for high-speed vehicles in waves. Journal of Ship Research 20 (4), 190 - 198.

Steinmann, P., Fach, K., Menon, B., 1999. Global and slamming sea loads acting on an $86 \mathrm{~m}$ high speed catamaran ferry. In: Proceedings of the 5th International Conference on Fast Sea Transportation, Seattle, USA. 
Sun, H., Faltinsen, O.M., 2008. Asymmetric water entry of a bow-flare ship section with roll angle. In: Proceedings of the IUTAM Symposium on Fluid-Structure Interaction in Ocean Engineering, edited by E. Kreuzer, Hamburg.

Streeter, V.L. (Ed.), 1961. Handbook of Fluid Dynamics. McGraw-Hill.

Thomas, G.A., Davis, M.R., Holloway, D.S., Watson, N.L., Roberts, T.J., 2003. Slamming response of a large high-speed wave-piercer catamaran. Marine Technology 40 (2), $126-140$.

Troesch, A.W., Kang, C.-G., 1988 Evaluation of impact loads associated with flare slamming. SNAME STAR Symposium, Pittsburgh.

Veen, D.J., 2010 A Smoothed Particle Hydrodynamics Study of Ship Bow Slamming in Ocean Waves. Ph.D. thesis, Centre for Marine Science and Technology, Curtin University.

Veen, D.J., Gourlay, T.P., 2011. A 2D Smoothed Particle Hydrodynamics theory for calculating slamming loads on ship hull sections. In: Proceedings, Innovation in High Speed Marine Vessels, Fremantle, March 2011. Published by the Royal Institution of Naval Architects.

Vulovich, R., Hirayama, T., Toki, N., Mizuno, H., 1989. Characteristics of hull stresses measured on a large containership in rough seas. Transactions of the Society of Naval Architects and Marine Engineers 97, 397 - 428.

Wagner, H., 1932. The phenomena of impacts and sliding on liquid surfaces. NACA translation 1366, National Advisory Committee for Aeronautics, Washington.

Whelan, J.R., 2004. Wetdeck slamming of high-speed catamarans with a centre bow. $\mathrm{PhD}$ Thesis, School of Engineering, University of Tasmania, Hobart.

White, F.M., 1999 Fluid Mechanics, $4^{\text {th }}$ Ed. McGraw-Hill.

Yamamoto, Y., Iida, K., Fukusawa, T., Murakami, T., Arai, M., Ando, A., 1985. Structural damage analysis of a fast ship due to bow flare slamming. International Shipbuilding Progress 32 (369), $124-136$.

Zhao, R., Faltinsen, O.M., 1993. Water entry of two-dimensional bodies. Journal of Fluid Mechanics 246, $593-612$.

Zhao, R, Faltinsen, O.M., Aarsnes, J.V., 1996. Water entry of arbitrary twodimensional sections with and without flow separation. In: Proceedings of the 21st Symposium on Naval Hydrodynamics, Trondheim, Norway. 